\title{
Informação e memória de médicos-cultural: Portugal - Bahia - Brasil (patrimônio registrado em plataforma digital)
}

\author{
Information and memory of cultural doctors: Portugal - Bahia-Brazil \\ (patrimony registered in digital platform)
}

Zeny Duarte de Miranda ${ }^{1}$

${ }^{1}$ https://orcid.org/0000-0003-0365-6905. Universidade Federal da Bahia, Salvador, Bahia, Brasil. zenydu@gmail.com

\section{Resumo:}

Trata-se de pesquisa cujo objetivo é demonstrar apontamentos para a sistematização e aplicabilidade Apresentar-se-á investigação sobre informação e memória de médicos-cultural, portugueses e brasileiros que produziram para além da Medicina, em Portugal e no Brasil, no período de 1808 até a atualidade, a partir de dados acerca de seus acervos documentais. A interdisciplinaridade se fará presente por tratar-se de investigação relacionada com diversas áreas do saber. Disponibilizar-se-á metodologia dos estudos e o modelo da plataforma digital SiS Médicos e a Cultura - Portugal e Bahia. Os acervos serão apresentados em seus formatos originais, analisados com vista à detecção das técnicas adotadas na sua organização, dos sistemas de informação e instrumentos de pesquisa utilizados pelas instituições detentoras e/ou por outros espaços guardiões. Demonstrar-se-á, a citada plataforma digital, a partir da descrição contextualizada dos acervos de médicos portugueses e baianos representantes da classe de cientistas e que produziram para além da ciência. No espaço constituído pela plataforma, para cada médico relacionado, será apresentada a "biobibliocronologia". São muitas as personalidades com o perfil assinalado. Portanto, não se esgotará, de uma só vez, a inclusão total desses cientistas, intelectuais das humanidades. Serão apresentadas as aberturas de campos com hyperlinks na WEB, para a leitura da vida, obra, pensamento e acervos documentais de médicos-cultural.

Palavras-chave: Memória. Informação. Ciência da Informação; Arquivos Pessoais; Medicina; Médicos; Plataforma Digital - SiS Médicos e a Cultura.

\begin{abstract}
:
This is research whose goal is to show notes for the systematization and applicability Will present information and research medical-cultural memory, Portuguese and Brazilians who produced beyond Medicine, in Portugal and in Brazil, in the period from 1808 until nowadays, from data about their documentary collections. Interdisciplinarity will be present as
\end{abstract}

IX Encuentro Ibérico EDICIC (Barcelona, 9 al 11 de Julio de 2019) 
various related research areas of knowledge. Will make available methodology of the studies and the digital platform model SiS doctors and culture - Portugal and Bahia. The collections will be presented in their original formats, evaluated for the detection of techniques adopted in your organization, information systems and research instruments used by the institutions holding and/or other spaces guardians. Will demonstrate, the digital platform, from the description of the collections of contextualized Portuguese and Bahian medical representatives of scientists and class that produced beyond the science. In space constituted by the platform, for each related medical, will be presented the "biobibliocronologia". There are many personalities with the profile. Therefore, you will be exhausted, at once, the total inclusion of these scientists, intellectuals of the humanities. The fields will be presented with hyperlinks on the WEB, for the reading of the life, work, thought and documentary collections doctors.

Keywords: Memory. Information. Information science; Personal Files; Medicine; Doctors; Digital platform-SiS Doctors and culture.

\section{INTRODUÇÃO}

A data 18 de fevereiro de 1808, possui grande significado histórico para Salvador da Bahia, Brasil, por ser ela a recordar a passagem de D. João VI em Salvador e, na altura, ter ele assinado o decreto da fundação da primeira escola de nível superior da Bahia, a então Escola Médico-Cirúrgica. Em 3 de outubro de 1832, a mencionada Escola foi designada Faculdade de Medicina da Bahia, hoje pertencente à Universidade Federal da Bahia. Assim rememora Jacobina (2008,p.12):

A Escola de Cirurgia, criada em 18 de fevereiro de 1808, funcionou de modo muito rudimentar nos seus primeiros anos, segundo um dos seus memorialistas, Malaquias Álvares dos Santos (1810-1856), autor da Memória histórica referente ao ano de $1854^{1}$. Com menos de oito anos a escola já necessitou de sua primeira reforma, com a carta régia de 29 de dezembro de 1815. Nessa reforma, o sistema de ensino médico mudou, aumentando o curso de quatro para cinco anos de duração e de três para cinco cadeiras ${ }^{2}$. O principal responsável pelas mudanças foi o Conselheiro Manuel Luiz Álvares de Carvalho, baiano, físico-mor e Diretor geral dos estudos médicocirúrgicos do Reino Unido de Portugal, Brasil e Algarve ${ }^{1}$.

\footnotetext{
${ }^{1}$ SANTOS, MA. Memória Histórica da Faculdade de Medicina da Bahia relativa ao anno de 1854. Rio de Janeiro: Imprensa Nacional, 1905.

${ }^{2}$ OLIVEIRA ES. Memória histórica da Faculdade de Medicina da Bahia, concernente ao ano de 1942. Salvador: Centro Editorial e Didático da UFBA, 1992.
}

IX Encuentro Ibérico EDICIC (Barcelona, 9 al 11 de Julio de 2019) 
Dessa instituição, surgiram grandes nomes das diversas áreas das humanidades, médicos por ela formados, impulsionadores à produção de outros saberes para além da ciência. A exemplo, Rita Lobato Velho Lopes, primeira mulher brasileira a cursar uma faculdade e a obter o título de médica, num período antagônico às ambições femininas (segunda metade do século XIX, Brasil Imperial, e primeiras décadas do século XX). Sobre Rita Lobato, destaca-se a sua determinação e coragem, o que a possibilitou conquistar o direito de participar da vida política, social e cultural do Brasil, deixando importantes legados à sociedade. "Uma mulher extraordinária, médica, feminista e política brasileira... nas eleições de 1934, aos 67 anos de idade, foi eleita como primeira vereadora de Rio Pardo - Rio Grande do Sul”. (SILVA; COELHO, 2016, p.140). Rita Lobato, foi a segunda médica titulada na América do Sul. Outros nomes de médicos formados pela Faculdade de Medicina da Bahia, apresentam expressões e conquistas femininas e masculinas relativas à cultura, literatura, artes, leis, política, religião, ciência e demais espaços que transcendem as áreas da Medicina. Com relação aos médicos formados por escolas médicas de Portugal, do mesmo modo, é volumosa a presença de médicos portugueses atuantes nas diversas áreas das humanidades, em âmbito geral.

Como breve retrospectiva, apresenta-se aqui a síntese de uma trajetória de pesquisa de pósdoutorado desta signatária, realizado na Universidade do Porto - Portugal, em 2006, denominada Os médicos e a cultura: estudo crítico e guia geral dos arquivos de médicos escritores, artistas e pensadores de Portugal e Bahia - Brasil (1808/2008), com bolsa concedida pela Fundação para a Ciência e Tecnologia (FCT).

Posteriormente, em 2008, devido a renovadas experiências, os estudos transmutam-se para um novo patamar científico denominado Os Médicos e a Cultura em Portugal e no Brasil, Bahia, 18082012, alargando-se à atualidade, por entender o objeto como uma "obra aberta"3, ficando, de

\footnotetext{
3 ...Umberto Eco (1972) defende que os processos de leitura e interpretação não podem pressupor uma análise pré-definida e estruturada do texto. Pelo contrário, implicam uma acentuada liberdade por parte do leitor, que é também receptor, tornando-se tarefa sua extrair dele uma análise pessoal. De acordo com tal noção, a origem do termo obra aberta advém da necessidade, cada vez mais patente, de se compreender e valorizar a capacidade criativa e interpretativa que conduz, sempre que necessário, a uma reestruturação do pensamento.
}

IX Encuentro Ibérico EDICIC (Barcelona, 9 al 11 de Julio de 2019) 
imediato, convertido em título de uma trajetória à sua implementação e, possivelmente, sine die a duração do que daí resultasse a realização dos estudos de pós-doutorado já assinalados.

\section{O NÚCLEO DA PESQUISA}

O objetivo desta pesquisa cabe em um só projeto e legitima o propósito primordial de acolher e concentrar os nomes de médicos baianos e portugueses, formados em Portugal e na Bahia que se deixaram encantar pelos apelos sedutores das Musas... (DUARTE; SILVA, 2016). A informação e memória de médicos-cultural, pela riqueza de suas vidas, obras, pensamentos, refletidos em seus acervos documentais por eles acumulados, durante dois séculos, de 1808, por considerar o ponto de partida desta pesquisa, e como forma de preservar, alhures, o episódio da criaçãoção da EscolaMédica da Bahia, influenciada em sua origem, pelo formato das escolas médico-cirúrgicas de Portugal.

A questão vem a tona: Por que esta temática encontra-se no âmbito da Ciência da Informação? No percurso desta pesquisa, a descoberta da temporalidade e da similaridade de costume, moda e comportamento, de médicos da Bahia e de Portugal, em devotassem à outras possibilidades de expressão de vida, apresenta riqueza de produção cultural (voltada às humanidades), reúne incomensurável acumulação de acervos documentais, capazes de destinar legado informacional desconhecido e, muitas vezes, trancados intramuros em residências e/ou instituições pelas quais tiveram assentos os médicos com o perfil assinalado. Aí se encontra o eixo de imensa pertinência à pesquisa em Ciência da Informação, Arquivologia, Biblioteconomia, Documentação e Museologia, especificamente, na linha temática do Congresso ISKO 2019, Organização do conhecimento e memória: exploração e recuperação de documentação de valor patrimonial.

A primeira vez que se tomou consciência da noção de obra aberta foi no simbolismo da segunda metade do século XIX, com Verlaine. Ao contrário do que se verificava na Idade Média, marcada por um acentuado hermetismo, o que reflectia uma cosmologia amplamente hierárquica e de profunda rigidez, a noção de obra aberta defende que uma produção literária não se encontra de todo acabada em si mesma e plenamente definida enquanto estrutura finita mas, pelo contrário, possibilita diversas interpretações e reformulações. http://edtl.fcsh.unl.pt/encyclopedia/obra-aberta/

IX Encuentro Ibérico EDICIC (Barcelona, 9 al 11 de Julio de 2019) 
A partir deste ponto, atribui-se à memória um dos principais elementos de pesquisa e da prática do profissional da informação, uma vez avaliada à necessidade de preservação de arquivos, bibliotecas, museus e demais instituições documentais ou unidades de informação, bem como a disseminação da experiência coletiva numa conjuntura social e ao longo dos tempos. Assim deuse a origem desta pesquisa, ampliada ao que se espera da era digital, esta realidade impõe estabelecer mudanças de paradigma social e, neste caso, mudanças de paradigma das áreas da Informação e Comunicação. Os recursos das Tecnologias de Informação e Comunicação (TIC), têm como função básica, reunir e preservar documentos relativos à propagação de conhecimentos e registros por entre as subsequentes gerações, representando essencial importância ao contexto prático do profissional da informação.

Nunca se teve tanta e tão disponível informação sobre uma infinita possibilidade de saberes. O volume documental assusta e a acessibilidade se faz tão evidente que o homem hoje vive um turbilhão de possibilidades informativas, especialmente por conta da acelerada transformação das TIC e, precisamente, da Internet e suas redes, passando a ampliar a necessidade de conhecimento cada vez mais e melhor. Uma intenção claramente determinada pelo tempo em que foi assumida - um tempo tecnológico intenso e vertiginoso em que somos impelidos pelos "cliques" velozes de dedos frenéticos em teclados vindos de paragens já não assim tão distantes da "fícção científica" (ou seja da Utopia...). Com efeito, identificar, referenciar e incluir listagens ou até quantidades ilimitadas de documentos digitalizados tornou-se inevitável no âmbito das TIC e, mais precisamente, na Galáxia Internet, como a designou sugestivamente o sociólogo catalão Manuel Castells (2004). (DUARTE; SILVA,p.23).

Esta comunicação propõe refletir sobre memória de médicos a partir dos seus arquivos pessoais e respectivas interpretações aliadas à análise contextualizada da documentação por eles acumulada e, devidamente, mapeada por este estudo, muitas vezes até, guardada em suas próprias residências, e, por vezes, em mãos de familiares ou de terceiros e, sem divulgação. E, como bem disse o famoso historiador português Hélder Pacheco "certos homens são cometas, são estrelas ou raios de luz" (MOREIRA, 2012). Assim, a herança documental-cultural deixada pelo incalculável número de médicos insignes da sociedade de Portugal e da Bahia torna-se impossível de, neste texto, ser 
apresentada. Há complexidade nas tramas do espaço-temporal devido a rica produção dessas mentes médicas que transcederam o mundo da ciência, voltando-se ao universo dos múltiplos saberes e múltiplas adoções de forma de viver a vida. Citando caso análogo, o médico português José Tomás de Sousa Martins (Sousa Martins),

foi orador brilhante, dotado de humor e inteligência, homem de actividade inesgotável e praticante incansável da caridade junto aos mais desfavorecidos, exerceu uma forte influência sobre os colegas de profissão, os alunos e os pacientes que tratou. Esta influência metamorfoseou-se e perpetuou-se no tempo, tendo a figura de Sousa Martins assumido contornos de santo laico, num culto actual, bem visível nos exvotos colocados em torno da sua estátua no Campo dos Mártires da Pátria, em Lisboa, e no cemitério de Alhandra, onde está sepultado. Foi sócio correspondente da Academia Real das Ciências de Lisboa. (HOSPITAL SÃO JOSÉ - LISBOA).

A título de ilustração, segue um dos exemplos da descrição da análise contextualizada sobre vida, obra, pensamento e acervo documental do médico-santo acima referenciado, extraído da plataforma digital WEBSISMEDICOS (2019):

Parte do acervo particular de Sousa Martins encontra-se no Hospital São José, Lisboa. Não existe precisão nas informações recolhidas acerca dessa documentação. Não foi possível dispor de informações precisas acerca do acervo pessoal deixado por Sousa Martins ao Hospital. É na Casa-Museu Dr. Sousa Martins, localizada na Freguesia de Alhandra, Concelho de Vila Franca de Xira, sito na antiga casa do famoso médico, professor e farmacêutico, que se pode encontrar, além da casa onde Sousa Martins viveu, várias exposições permanentes, incluindo a de documentos e objetos de uso pessoal do Dr. Sousa Martins.

De milhares de nomes, destacamos alguns dos médicos-cultural e seus acervos: De Portugal: ADELAIDE DE JESUS DAMAS BRAZÃO CABETE (ADELAIDE CABETE); DOMITILA HORMIZINDA MIRANDA DE CARVALHO (DOMITILA DE CARVALHO); MIGUEL AUGUSTO BOMBARDA; JOSÉ LEITE DE VASCONCELOS CARDOSO PEREIRA DE MELO (JOSÉ VASCONCELOS); EGAS MONIZ ANTÓNIO CAETANO DE ABREU FREIRE (EGAS MONIZ); ABEL SALAZAR; DANIEL DOS SANTOS PINTO SERRÃO (DANIEL 
SERRÃO). Da Bahia - Brasil: RITA LOBATO; NISE MAGALHÃES DA SILVEIRA (NISE DA SILVEIRA); FRANCISCA PRAGUER FRÓES; JULIANO MOREIRA; EDGARD DO RÊGO SANTOS (EDGARD SANTOS); JOSÉ SILVEIRA; RODOLFO TEIXEIRA.

\section{TRAÇO METODOLÓGICO}

A sessão metodológica procurou anunciar os procedimentos científicos e os percursos percorridos durante o desenvolvimento da pesquisa. Esta seção apresenta, preliminarmente, os mecanismos de recuperação da informação que têm subsidiado a pesquisa em foco; os métodos de abordagem e procedimento; o nível da pesquisa, as técnicas e os instrumentos adequados à problemática do projeto, incluindo o objeto de estudo. A partir das abordagens qualitativa, do fenômeno informacional, e quantitativa aplicáveis, o estudo apresenta conteúdo voltado à memória de médicos, permeada pelas ações de cientistas e por suas expressões religiosas, políticas e culturais, em Portugal e no Brasil, observando pontos relacionados com a integridade e inteligibilidade de seus arquivos, bibliotecas, museus e "biobliocronologia". Estas possuem maior incidência em informações que colocam aspectos especiais quanto à vida, obra e pensamento de homens singulares e, ao mesmo tempo, plurais. Em particular, será dada ênfase ao modus vivendi do médico, com avaliação tanto retrospectiva quanto prospectiva do fluxo informacional dos acervos documentais analisados e a aplicação de modelos desenvolvidos em plataforma digital. Este estudo vai para além da formalização de um sistema de informação digital, aproxima-se do que hoje se entende por plataforma digital e apresenta o SiS Médicos e a Cultura-Portugal e Bahia - Brasil, com a permissão de acesso a outros tantos médicos-cultural.

Nesta apresentação, interessa avaliar o contributo dos médicos para outras áreas através da análise documental contextualizada. E, por conseguinte, apontar para a necessária interlocução entre as áreas, nas etapas de leitura e interpretação dos dados coletados em unidades de informação. Neste caso, a plataforma digital SiS Médicos e a Cultura - Portugal e Bahia - Brasil, é fundamental à veiculação da informação. Para BRANCO (2018,p.90),

IX Encuentro Ibérico EDICIC (Barcelona, 9 al 11 de Julio de 2019) 
A escolha e a adoção de uma nova plataforma de acesso à informação, neste caso com colaboração participativa do usuário, amplia a disseminação dessa ferramenta dando oportunidade ao interessado de participar ativamente da construção desse arcabouço informacional. A Internet sendo um recurso tecnológico de extrema importância na sociedade moderna, contribuirá de forma expressiva para a rápida disseminação do WEBSISMEDICOS e consequentemente sua proposta de acesso democrático e universal à informação. A nova interface, mais dinâmica $\mathrm{e}$ clean, permite ao usuário ter acesso a ferramentas úteis para sua pesquisa, além de franquear a acessibilidade nas mais diversas plataformas de dispositivos: smartphones, tablets, netbooks, notebooks e desktops. O acesso ao WEBSISMEDICOS por meio dos dispositivos mencionados dá ao usuário maior independência nas questões espaço-temporais: o acesso às informações relativas aos médicos podem ser feitas em qualquer tempo e em qualquer lugar.

O projeto suscita análises comparativas entre os dois países, Portugal e Brasil, pois é possível enxergar as convergências e divergências no fazer cultural dos médicos assinalados, portugueses e brasileiros. Todavia, esta pesquisa promove algumas reflexões: A presença do fazer arte, literatura, cultura... estimula a sensibilidade do médico no seu atuar? De fato, existe uma dicotomia estanque entre o médico que exerce a Medicina e o médico cultural?

\section{AO PRINCÍPIO... UM PROJETO MULTIPLICADO}

Nesta pesquisa, foi necessário rever o significado atribuído ao termo cultura, levando em conta sua carga iluminista e dual do conceito (cultura versus natureza), bem como sua acepção mais comum associada à produção artística, filosófica, literária de um povo. Nesse contexto, os estudos sobre conceito de cultura e informação se relacionaram ao âmbito da área da Medicina, estabelecendo o que se espera de um titular de arquivo, biblioteca, ou quaiquer que sejam acervos documentais, com sua carga científica, de base e, em sua busca pelo lúdico das artes, literatura, música, ou mesmo por caminhos diversos, a exemplo da religião e da política. Alicerçados no conceito de cultura de Edgar Morin (1962), quando este autor discute o papel do autor em sua própria construção do saber acrescentando que o o criador armava-se exactamente no começo da era industrial, e tende a confundir-se com produção.

IX Encuentro Ibérico EDICIC (Barcelona, 9 al 11 de Julio de 2019) 
No entanto, fica evidente a existência das dimensões de capital cognitivo, mitológico, ritualístico e técnico que engloba toda a produção de saberes do homem, sendo todo esse processo representado e materializado em objetos, costumes e documentos. Portanto, para efeito deste estudo, em nível interdisciplinar, o objeto de estudo da Ciência da Informação englobaria todas essas dimensões do capital cultural humano, sendo o objetivo analisar justamente as tensões e simbioses entre a Ciência da Informação, Ciências da Saúde e Cultura.

No transcorrer, são apresentados exemplos de médicos que também são escritores e filósofos, sendo eles muitas vezes atraídos para as artes em função do estresse da profissão, encontrado na universo da cultura um refúgio intelectual. No levantamento biográfico realizado, apontamos para um aspecto importante trazido a partir da obra de Botelho 1991, Médicos na toponímia de Lisboa - o papel da mulher no contexto da Medicina, exempificado pela marcante presença de médica portuguesa Adelaide Cabete e da médica brasileira Rita Lobato. A primeira, Adelaide Cabete, descrita como uma mulher destemida, empreendedora e defensora dos oprimidos e do feminismo, formou-se em Medicina na Escola Médico-Cirúrgica de Lisboa (1900), com a tese de licenciatura A proteção às mulheres grávidas pobres. Foi uma professora de grande prestígio no Instituto Feminino de Odivelas e escritora de diversos artigos nos quais defendia seus ideais republicanos, tendo dirigido a revista Alma feminina. A segunda, Rita Lobato, com rica biografia, foi a primeira médica formada na Escola Médica da Bahia, anteriormente citada.

Este estudo traz diversos outros exemplos de nomes da Medicina, de Portugal e do Brasil, que produziram para além da ciência, sendo uma fonte inesgotável de conhecimento que nos ajuda a entender e admirar a cultura desses dois países, transportadas ao mundo, por meio de plataforma digital.

Como um "um vislumbre impressionista" (DUARTE \& SILVA,2016), os autores trazem exemplos de médicos que também são escritores e filósofos, sendo eles muitas vezes atraídos para as artes em função do stress da profissão, encontrado na escrita um refúgio intelectual. Um dos exemplos

IX Encuentro Ibérico EDICIC (Barcelona, 9 al 11 de Julio de 2019) 
trazidos foi o do médico, cientista, escultor, pintor, filósofo e professor universitário, Abel de Lima Salazar, homem à frente do seu tempo, defensor de ideias progressistas e combatente da ditadura de António de Oliveira Salazar, coincidentemente seu homônimo. No cenário mais atual, temos o José António de Melo Gomes, médico, escritor e artista plástico, Gomes busca em seus trabalhos alinhar seu conhecimento científico com sua produção artística.

4 MEMÓRIA - MÉDICOS CULTURAL

Como resultados, apresentar-se-á reflexão sobre memória e cultura, com o fito do resgate da biobliocronologia de médicos, e seus acervos documentais, com o perfil mais do que voltado à ciência (médico cultural), quer da implementação da análise, descrição e compartilhamento de informação por meio de arquivos, bibliotecas, museus, casas-museus, entre outras constituídas instituições, guardiãs de acervos documentais de cientistas, mais que cientistas.

No contexto atual científico onde se tem cada vez mais buscado a integração dos saberes, esta pesquisa coloca-se como oriunda da perspectiva interdisciplinar do fazer científico. Nesse sentido, a proposta de estudar as relações entre informação e cultura no fazer dos médicos em Portugal e na Bahia traz contribuições importantes para várias áreas do saber, nomeadamente, à Ciência da Informação, Medicina e Ciência da Computação. Algumas reflexões importantes que podem ser indagadas partir desta pesquisa é a questão dos acervos documentais de médicos pesquisados, espaços que retratam médicos cultural, com produções nas mais distintas áreas e no decorrer das suas vidas pessoais.

O conceito de médicos cultural, introduzido por Duarte; Silva (2016), deu-se a partir dos estudos registrados no livro citado, obtendo como resultado a implementação da plataforma digital www.websismedicos.ufba. A pesquisa realizada aponta para a condição de inúmeros médicos exercerem suas funções a um passo do que se pode denominar de processo de criação em outras áreas, mais especificamente, da cultura. Através dos arquivos pessoais por eles acumulados, nos foi possível estabelecer contato com mundos outros vivenciados por médicos com o perfil

IX Encuentro Ibérico EDICIC (Barcelona, 9 al 11 de Julio de 2019) 
assinalado, na medida em que o titular passa a agrupar documentos resultantes de conjuntos de atos, em concordância com o seu modo de vida, no âmbito público e privado, itens documentais dispostos próximos ou distantes, segundo uma necessidade presumida ou a constância dos acontecimentos.

Esses documentos representam sempre o vínculo pessoal que o titular menteve com o mundo. $\mathrm{O}$ indivíduo guarda documentos que testemunham momentos de sua vida, suas relações pessoais ou profissionais. Porque, a memória e o patrimônio são trabalhados e concebidos para garantir a cidadania cultural. $\mathrm{O}$ direito à memória e a memória como trabalho de criação das obras históricas no pensamento e nas artes, no cotidiano e nos textos, nos objetos acumulados e nas relações sociais, é reconhecido não por quem o reúne, mas, essa é função destinada ao profissional da informação, a partir do conhecimento teórico e prático da arquivologia e do imbricamento desta com as ciências sociais aplicadas e, consequentemente, com a cultura. E, nessa direcção, Chauí (1992, p.39), acrescenta:

A cultura é por nós entendida sob um duplo registro: no sentido antropológico amplo de invenção coletiva e temporal de práticas, valores, símbolos e ideias que marcam a ruptura do humano em face das coisas naturais com a instituição da linguagem, do trabalho, da consciência da morte e do tempo, do desejo como diverso da necessidade, do poder como diverso da força e da violência, do pensamento como diferenciação entre o necessário e o possível, o contraditório e o idêntico, o justo e o injusto, o verdadeiro e o falso, o belo e o feio e o mau, a determinação ética da existência pela liberdade e pela culpa, a determinação política da existência pelo trabalho realizado sobre as diferenças e conflitos sociais.

Então, o arquivo pessoal, assim visto, passa a representar uma espécie de baú cultural em pirâmide. Guarda a memória do titular e a de seu tempo para as gerações futuras, podendo transmitir muito mais do que se imagina. A partir da ordenação de um conjunto documental, este poderá revelar não apenas trajetória de vida, como também gostos, hábitos e a temporalidade de seu titular. O movimento do titular é dominado por uma subjetividade que recorta, costura e prolonga percepções momentâneas. Sua lógica emerge da região histórico-afetiva onde o mundo íntimo se mistura com o mundo público. Ao mesmo tempo, esses documentos contribuem ao resgate e à recuperação da

IX Encuentro Ibérico EDICIC (Barcelona, 9 al 11 de Julio de 2019) 
memória individual e, consequentemente, social, histórica e cultural, além de proporcionar desenvolvimento na pesquisa artística, científica e tecnológica.

Por outro lado, notamos que acadêmicos, intelectuais, escritores, médicos, políticos, artistas, homens públicos, têm demonstrado maior interesse pela preservação de seus próprios documentos e mais consciência do valor deles para a história e a cultura. Alguns já assumiram a transferência de seus arquivos para instituições documentais, onde tais acervos possam ser organizados e disponibilizados. E, os arquivos pessoais, de interesse público e social, identificados como fontes relevantes para a história e a evolução científica nacional ficam melhor se depositados em instituições documentais públicas. Assim, deixam de ser apenas pessoais/domésticos e passam ao âmbito da ampla divulgação e, não tendo ultrapassado o período do sigilo/reserva, resta aguardar este tempo ou, em alguns casos, solicitar autorização do titular ou do tutor imediato.

Além destas, outras reflexões poderão surgir levando em conta o objetivo principal desta investigação. Interessa conhecer arquivos pessoais, especificamente de médicos que deixaram importantes legados artísticos e culturais para o mundo. Por fim, os estudos apresentam o compartilhamento de banco de dados / portal, capaz de veicular informação e conhecimento, a quem possa interessar.

\section{PLATAFORMA DIGITAL DE MÉDICOS CULTURAL}

O lançamento e a disponibilização da plataforma SiS Médicos e a Cultura em Portugal e na Bahia, na Internet, leva o nome de WEBSISMEDICOS, pelo novo formato em que essa plataforma alcançou, após estudos aprofundados do pesquisador Daniel Branco e pela contribuição da pesquisadora Eneida Bauman. Após reconfiguração do sistema, Branco (2018, p.90), registra:

O acesso ao sítio WEBSISMEDICOS por meio dos dispositivos mencionados dá ao usuário maior independência nas questões espaço-

IX Encuentro Ibérico EDICIC (Barcelona, 9 al 11 de Julio de 2019) 
temporais: o acesso às informações relativas aos médicos podem ser feitas em qualquer tempo e em qualquer lugar.

Assim renovada a plataforma digital a ser apresentada neste Congresso ISKO - 2019, propõe potencializar efeito multiplicador de pesquisas Multi e Inter e Transdisciplinares (MIT) em nível dos pilares da academia universitária (ensino, pesquisa, extensão e inovação). Visto nesta dimensão, a plataforma, pela profícua cooperação luso-brasileira, conveniada e cada vez mais enraizada e sólida, será socializada nas páginas da Universidade Federal da Bahia e Universidade do Porto, ultrapassando para além do Atlântico e, dessa forma, rompendo barreiras geográficas.

Outras questões nos fazem refletir, sendo o processo de criação dos médicos cultural um tanto quanto instigante e enigmático, no que diz respeito às escolhas entre produzir apenas ciência ou abandoná-la ou juntá-la à produção das artes e da cultura, de uma maneira geral. No cenário contemporâneo, permeado pelas tecnologias digitais os acervos documentais dos médicos cultural estão preservados para as gerações futuras? A Medicina reconhece a Ciência da Informação como protagonista na gestão de documentos e compartilhamento da informação? Esses médicos cultural já estão no contexto de um pensamento pós-custodial?

Nesse contexto, esta pesquisa, iniciada em 2006, tomou um rumo mais avançado, acolhendo estudos sobre as tecnologias da informação e comunicação, com o fito de promover o compartilhamento dos dados informacionais acerca da vida, obra, pensamento e acervos documentais de médicos cultural, organizado-os e transportando-os ao mundo por meio da plataforma digital.

Até chegar ao estágio atual, o mencionado sistema passou por experimentações. A primeira versão, em 2008, teve uma interface possível para a época, porém espartana e clássica para os padrões técnicos vigentes - http://www.medicoseacultura2.ufba.br/ .

IX Encuentro Ibérico EDICIC (Barcelona, 9 al 11 de Julio de 2019) 
A segunda versão, em 2010, aprimorou-se a relação com o internauta através dos recursos webnode: http://medicoseacultura.webnode.com.br/ - com o sistema por trás desta nova interface - em backoffice.

Na terceira versão, em 2014, surge o projeto piloto com a transferência dos dados inseridos nos SiS Médicos e a Cultura à uma nova plataforma WIKI: http://pt-br.sismedicos.wikia.com/wiki/wiki_sis_médicos. Esta versão serviu muito bem para os diversos testes que foram efetuados, mas apresentou vários inconvenientes em relação ao registro da licença de uso e a profusão de mídia paga que constantemente poluíam as páginas. Estes entraves não condiziam com a proposta de uma apresentação de plataforma colaborativa de um grupo de pesquisa (G-Acervos) de uma instituição acadêmica para uma comunidade acadêmica e profissional.

As duas últimas versões beta foram baseadas na obtenção do referencial técnico-conceitual da web semântica, metadados, taxonomia e ontologia que podem ser encontrados no seguinte trabalho hospedado no site: http://www.ufrgs.br/sismed/wiki/index.php/projeto:semanticmediawikinosis_médicos, desenvolvido pelo Prof. Dr. Rafael Port da Rocha da UFRGS:

Atualmente, o BD SISMEDICOS encontra-se migrado de MSSQL (Microsoft) para MYSQL (open source), estando o banco hospedado em servidores da Superintendência de Tecnologia e Informação (STI) órgão responsável por toda a gestão tecnológica informacional da Universidade Federal da Bahia (UFBA), lançado e disponibilizado em páginas oficiais da UFBA e da U.Porto, assim como amplamente acessível nas núvens.

Para o usuário preencher mais ativamente o BD do SISMEDICOS, optou-se pela plataforma colaborativa MEDIAWIKI, instalada também nos servidores do STI/UFBA no domínio www.websismedicos.ufba.br atualizando desta forma o conceito de cloud (nuvem) permitindo que as barreiras geográficas fossem quebradas, isso é, em um primeiro momento, as pessoas - médicos

IX Encuentro Ibérico EDICIC (Barcelona, 9 al 11 de Julio de 2019) 
e afins - da Comunidade dos Países de Língua Portuguesa (CPLP) poderão ajudar a construir este arcabouço informacional contribuindo assim para a universalização de seu acesso.

O SiS Médicos e a Cultura demonstrado em MEDIAWIKI, acompanha a compreensão teórica e conceitual da citada plataforma, e apresenta algumas extensões que serão implementadas posteriormente à ação de conexão do BD às páginas do sítio, tais como:

\begin{tabular}{|l|l|}
\hline EXTENSÃO: & ENDEREÇO: \\
\hline A - Maps & https://www.mediawiki.org/wiki/Extension:Maps \\
\hline B - Timeline & https://www.mediawiki.org/wiki/Extension:EasyTimeline \\
\hline C - Graph & https://www.mediawiki.org/wiki/Extension:Graph \\
\hline D - Multimedia & https://www.mediawiki.org/wiki/Extension:MultimediaViewer \\
\hline
\end{tabular}

Tabela - Elaboração própria da autora

De acordo com o sítio www.mediawiki.org, a extensão MAPS (letra A da tabela acima) permite que suas páginas MEDIAWIKI visualizem dados geográficos com APIs de mapeamento dinâmicas e baseadas em JAVASCRIPT, como o GOOGLE MAPS, OPENSTREETMAP e OPENLAYERS em suas páginas wiki. Possui suporte integrado para geocodificação, exibição de mapas, exibição de marcadores e formas geoespaciais, adicionando pop-ups e mais e permite uma ampla personalização por mapa ou para todos os mapas no seu wiki.

O EASYTIMELINE (letra B da tabela acima) é um atributo que produz uma imagem a partir de um wikitexto. A imagem pode ser um diagrama unidimensional (horizontal ou vertical) ou uma unidade bidimensional. [...] Uma lista detalhada dos eventos e datas em forma tabulada pode oferecer ao leitor uma grande quantidade de detalhes, mas pode deixar de fornecer uma visão geral, com grande perspectiva.

A extensão GRAPH (letra C da tabela acima) permite que uma marca <Graph> descreva visualizações de dados, como gráficos de barras, gráficos de torta, linhas de tempo e histogramas (demo) em um formato JSON que renderiza um gráfico baseado em VEGA. [...] A extensão de gráfico permite que gráficos poderosos da VEGA sejam adicionados às páginas do wiki. Os

IX Encuentro Ibérico EDICIC (Barcelona, 9 al 11 de Julio de 2019) 
gráficos podem ser estáticos e interativos. A maneira mais fácil de adicionar um gráfico é usar um modelo pronto, como $\{\{$ Graph: Chart $\}$. Esses modelos escondem todas as complexidades da VEGA. Os usuários avançados podem usar o GRAPH SANDBOX para desenvolver gráficos. GRÁFICO SANDBOX permite a sintaxe do modelo wiki além de JSON.

A extensão MULTIMEDIAVIEWER (letra D da tabela acima) fornece ao usuário de um wiki uma interface diferente para visualizar imagens em tamanho real ou quase em tamanho real em seu navegador sem cargas de página estranhas ou páginas intermediárias confusas.

\section{REFERÊNCIAS}

Branco, Daniel J.B.C.. A plataforma WIKI no acesso à informação de arquivos pessoais e memórias de médicos. Dissertação (Dissertação em Ciência da Informação) - UFBA. Salvador, p.90. 2018.

Duarte, Zeny; Silva, Armando Malheiro da. Os médicos e a cultura em Portugal e na Bahia: olhar(es) introspectivo e analítico sobre o "modo de ser e de estar" médico-cultural. Salvador: EDUFBA, 2016.

Jacobina, Ronaldo; Castellucci, José; Pinto, Emerson; Melo, Eliane Maria Noronha. Os acadêmicos de Medicina e os 200 anos da Faculdade de Medicina da Bahia: da criação da escola em 1808 à participação na guerra do paraguai (1864-70). Salvador. Gaz. méd. Bahia 2008;78:1(Jan-Jun):1123.

Moreira, P. E.P. (2012). O pai da nutrição em Portugal. Life \& Style e Bem-Estar. Recuperado de http://lifestyle.publico.pt/nutricao/299999_emilio-peres-o-pai-da-nutricao-em-portugal.

Morin, Edgar. (1962). L 'Esprit du temps I. Névrose. Paris: Grasset, 283 páginas

Silva, Ademir; Teresa, Coelho. Rita Lobato: a primeira médica formada pela Faculdade de Medicina da Bahia. In: Os médicos e a cultura em Portugal e na Bahia: olhar(es) introspectivo e analítico sobre o "modo de ser e de estar" médico-cultural. Salvador: EDUFBA, 2016, p.140.

WEBSISMEDICOS UFBA, (2019). Recuperado de http://www.websismedicos.ufba.br/index.php?title=Jos\%C3\%A9_Thomaz_de_Sousa_Martins.

IX Encuentro Ibérico EDICIC (Barcelona, 9 al 11 de Julio de 2019) 